\title{
L LYSINE PRODUCTION BY CHEMICAL MUTAGENESIS OF HOMOSERINE DEHYDROGENASE OF DDH GENE IN Corynebacterium glutamicum ATCC13032
}

\author{
Bhushanam Vanasi ${ }^{1}$, Laxminarayana Eppakayala ${ }^{2}$ and Ramesh Malothu ${ }^{1, *}$ \\ ${ }^{1}$ Institute of Science and Technology, Jawaharlal Nehru Technological University Kakinada, \\ Kakinada, Andhra Pradesh India \\ ${ }^{2}$ Sreenidhi Institute of Science and Technology, Yamnampet, Ghatkesar, \\ Hyderabad-501301 Telangana, India \\ *E-mail: ramesh_biotech@jntuk.edu.in
}

\begin{abstract}
Auxotrophic mutant formed from ddh gene recombinant ATCC 13032 with blocked homoserine dehydrogenase showed increased yield of L Lysine of $24.89 \mathrm{~g} / \mathrm{l}$ from normal ddh gene recombinant ATCC 13032 strain which had a yield of $20.66 \mathrm{~g} / 1$ of L Lysine. The maximum yield of L Lysine for the auxotrophic mutant is attained at 7.5 PH, $30^{\circ} \mathrm{C}$ of temperature and an incubation time of $96 \mathrm{hrs}$. The Auxotrophic mutant of ddh recombinant C. glutamicum showed nearly $6.52 \mathrm{~g} / 1$ more amount of 1 lysine than Auxotrophic mutant of wild type with $18.57 \mathrm{~g} / 1$ of L Lysine. The Chemical mutagen ENU caused a mutation in the Homoserine serine dehydrogenase enzyme diverted the Aspartyl $\beta$ semialdehyde to bind with 2,3Dihydrodipicolinate synthase to participate in the L Lysine synthesis through 2,3 meso- Diaminopimelate (Meso-Dap). Being a recombinant for diaminopimelate dehydrogenase (ddh) the auxotrophic mutant for the homoserine dehydrogenase follows the ddh pathway by overexpression of ddh by deviating the Acetyltransferase and Succinyl transferase is the reason for the high yield of L Lysine production.

Keywords: Lysine, ddh, 2, 3-meso DAP, ATCC 13032.
\end{abstract}

(C) RASĀYAN. All rights reserved

\section{INTRODUCTION}

L Lysine is one of the most important essential amino acids which could be used in many biophysical mechanisms in living organisms. Corynebacterium glutamicum is used to produce L Lysine commercially. ${ }^{1}$ L-Lysine is an essential amino acid which is utilized in many biochemical reactions like phosphorylation and also used as an additive for fodder crops. ${ }^{2}$ Annually around 80, 00, 00 tones were produced which made L Lysine second among global amino acid synthesis at industrial scale. ${ }^{3,4}$ Chemical synthesis, enzymatic method, fermentation, extraction from protein Hydrolysate, genetic engineering and protoplast fusions were several kinds of technologies employed in L Lysine synthesis from Corynebacterium glutamicum ${ }^{3,26}$ L-lysine is one of the most deficient components found in the food of both human and animals. Animal feed generally contains a less quantity of L-lysine and is not synthesized by cattle, poultry or other livestock, so L-lysine will be added as a food supplement for animals to meet feed requirements. ${ }^{6}$ L-Lysine, one of the eight essential amino acids for animals and humans which is used as feed additives, dietary supplements and also as an ingredient of pharmaceuticals and cosmetic.,

Corynebacterium glutamicum is a non-lethal and non-emulsifying gram-positive bacterium. It exhibits a low protease activity in the culture and can secrete protease-sensitive proteins into the culture supernatant. ${ }^{14}$ C. glutamicum is a gram-negative bacteria with the absence of lipopolysaccharide removed in the production of therapeutic proteins ${ }^{15}$ increases the yield by reducing the purification steps. $C$. glutamicum is generally recognized as safe (GRAS) for the industrial biochemical production of L Lysine and L glutamate. ${ }^{16}$

Corynebacterium glutamicum is one of the major microorganisms used in amino acid synthesis. The Corynebacterium glutamicum is a rod-shaped bacteria, aerobic and gram-positive bacteria grows in the

Rasayan J. Chem., 13(1), 1245-1261(2020)

http://dx.doi.org/10.31788/RJC.2020.1325416

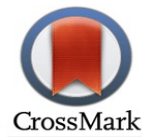


RASĀYAN J. Chem.

Vol. 13 | No. 2 |1245-1261| April - June | 2020

soil, on the surfaces of vegetables and fruits ${ }^{17} \mathrm{C}$. glutamicum has the capability to metabolize glucose, fructose, and sucrose. ${ }^{18,29}$ C. glutamicum utilizes many different kinds of carbohydrates, organic acids, and alcohol as a carbon and energy source for rapid microbial growth and for many amino acids synthesis. ${ }^{24},{ }^{25}$ The glucose, or sucrose or any carbon source is utilized by the Corynebacterium glutamicum for 1 lysine synthesis by fermentation. ${ }^{28}$ The time of incubation is reported for maximum L Lysine is between $48 \mathrm{hrs}$ to $72 \mathrm{hrs} .{ }^{30,31}$ The ddh recombinant Corynebacterium glutamicum ATCC 13032 produces more amounts of L Lysine compared to Wild type. This is because of the expression of more amount of ddh which acts as an enzyme for the substrate 2,6 dicarboxylic acid with the participation of less number of enzymes. Chemical mutagenesis with ENU increased the yield of L Lysine in the mutant than the Wild type strain. ${ }^{27}$ The ENU causes insertion or deletion mutation and shows its effect on protein synthesis. The ENU causes a mutation in Homoserine dehydrogenase gene to cause the Homoserine Auxotrophsof C. glutamicum. ${ }^{21}$

Generally, The Aspartyl $\beta$ semialdehyde is produced in two ways. In the Krebs cycle of Corynebacterium glutamicum , the Oxaloacetic acid (OAA) ${ }^{19,20}$ undergoes a transamination reaction with the presence of glutamate: oxaloacetate: transaminase enzymes produce aspartyl $\beta$ semi aldehyde which further produces homoserine and L L diaminopimelate (2,3 meso- DAP) by two different pathways ${ }^{1}$. The Aspartyl $\beta$ semialdehyde is also formed from Aspartate dehydrogenase from Aspartyl phosphate which was formed from Aspartate by Aspartate kinase. ${ }^{2,19}$ The aspartyl $\beta$-semi aldehyde acts as a common substrate to produce L Lysine through L L diaminopimelate(2,3-DAP)and Methionine or threonine through homoserine. ${ }^{1,28}$ The aspartyl $\beta$-semi aldehyde converts to Homoserine by reacting with homoserine dehydrogenase. ${ }^{4}$ which participates in the Homoserine pathway in the production of Threonine and Methionine. ${ }^{22,23}$ Homoserine reacts with $\mathrm{Met}^{6}$ and produces O- Acetylhomoserine which reacts with Met $B$ synthesize Cystathionine further reacts with $C^{7}$ to produce Homocysteine finally reacts with Met $E$ or Met $H$ to produce methionine or Homoserine reacts with homoserine kinase produces $\mathrm{L}$ homoserine phosphate and converts to threonine ${ }^{11}$ by Threonine synthase in Homoserine pathway. Aspartyl $\beta$ semi aldehyde reacts with 2,3 Dihydrodipicolinate synthase produces 2,3 Dihydropicolinate which further reduces to 2,6 Dicarboxylic acids by 2,3 Dihydrodipicolinate reductase. Corynebacterium glutamicum chose three kinds of enzymes namely Acetyltransferase or Succinyl Transferase or diaminopimelate dehydrogenase $(d d h)$ to produce $\mathrm{L} \mathrm{L}$ diaminopimelate $(2,3$ meso DAP). The LL diaminopimelate (2,3 meso DAP) converts to L Lysine by Lysine synthase. By Recombination with ddh gene with a constitutive promoter enhances the productivity of L Lysine by diverting the acetyltransferase and succinic transferase pathway to ddh pathway. The Chemical MutagenN-nitroso-N-ethyl urea(ENU) ${ }^{8,9}$ has the capability to cause deletion or insertion mutation in the Homoserine dehydrogenase $e^{18}$ enzyme and blocks the Homoserine Pathway which generally leads to the production of threonine and Methionine. This block in the homoserine pathway diverts the aspartic $\beta$-semialdehyde to react with 2,3 Dihydrodipicolinate synthase the enzyme to produce more amounts of $\sum$-diaminopimelate $\left(\sum \mathrm{DAP}\right)$ through ddh pathway.2,3 Dihydrodipicolinate synthase ${ }^{35}$ converts aspartic $\beta$-semialdehyde to 2,3 Dihydropicolinate. In the presence of reductase 2,3 Dihydropicolinate reduces to Piperidine 2,6, dicarboxylic acid. The formation of DAP will be done by binding of Piperidine 2,6, dicarboxylic acid with three different enzymes acetyltransferase or Succinyl transferase or diaminopimelate dehydrogenase enzymes leads to three different pathways for the L Lysine production through DAP. 2,6 dicarboxylic acid reacts with acetyl transferase produces the $\mathrm{N}$ - acetyl 2 -amino 6-keto L-pimelate which reacts with the enzyme aminotransferase produces N- Acetyl-L-L-diaminopimelate produces L-L-DAP by deacetylase in the acetyltransferase pathway which is a three-step pathway. 2,6 dicarboxylate reacts with Succinyl transferase to produce N Succinyl 2- amino 6 keto $\mathrm{L}$ pimelate which reacts with dap $C$ Produces $\mathrm{N}$ Succinyl - L-L diaminopimelate which again reacts with dap $E$ gives L L diaminopimelate is also a three-step pathway. The ddh recombinant strain produces moreL L diaminopimelate (2,3 meso DAP) by overexpression of ddh enzyme which follows ddh pathway for the production of $\mathrm{L} \mathrm{L}$ diaminopimelate (2,3 meso-DAP) by reacting with 2,6 Dicarboxylic acid as substrate by eliminating the more number of reactions that were in the remaining acetyl transferase and Succinyl transferase pathways by overexpression of $d d h$ by the ddh recombinant strain of C. glutamicum ATCC 13032 strain with constitutive promoter. The general events that took place in the Lysine production are illustrated in Fig. -1 . 
RASĀYAN J. Chem.

Vol. 13 | No. 2 |1245-1261| April - June | 2020
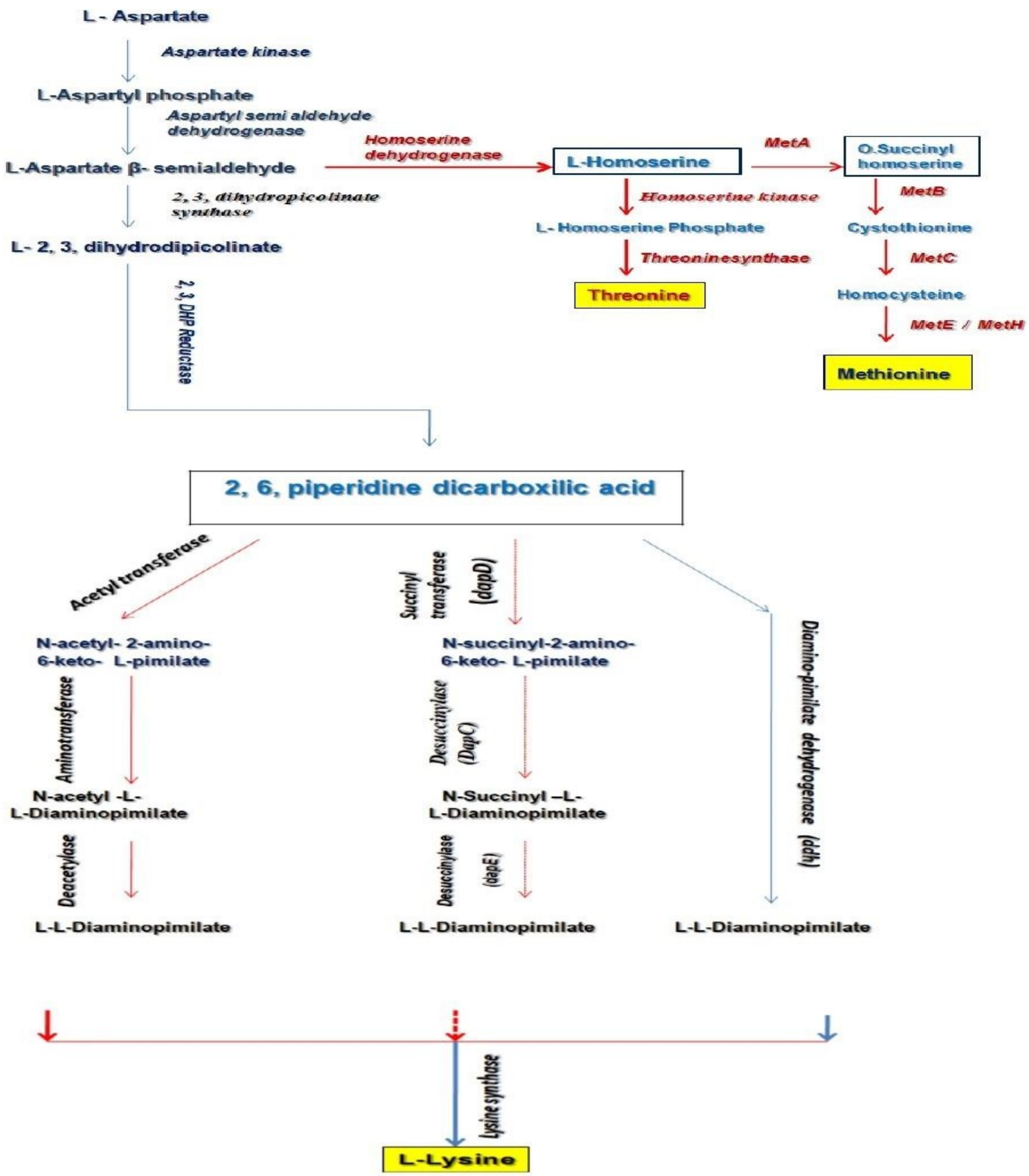

Fig.-1:The Homoserine Pathway for Threonine and Methionine Synthesis and Acetyltransferase, Succinyl Synthase and Diaminopimelate dehydrogenase Pathways in the Synthesis of L Lysine through L L diaminopimelate (2,3 meso- DAP)

\section{Bacterial Cell Cultures}

\section{EXPERIMENTAL}

The bacterial strain used in this research is a recombinant of ddh gene with a constitutive promoter of $C$. glutamicum (ATCC13032) developed by cloning ${ }^{32}$ in the lab of Ramesh Malothu, school of biotechnology, JNTUK which had an increased yield of $20.66 \mathrm{~g} / \mathrm{L}$ of 1-lysine.

Recombinant strain developed in our laboratory from the ATCC 13032 wild type C. glutamicum, by 
recombining $d d h$ gene with a constitutive promoter was utilized in the process of chemical mutagenesis with-nitroso-N-ethyl urea (ENU). The mutagenic power of N-ethyl-N-nitrosourea (ENU) stems from the generation of diazomethane. . $^{33,34}$

\section{Chemical Mutagenesis Method}

Seed culture medium (D-Glucose 10 g/l, Peptone 5 g/l, Yeast extract 3.75 g/l, NaCl 5 g/l, (NH4) SO $_{4} 17.5$ $\mathrm{g} / \mathrm{l}, \mathrm{K}_{2} \mathrm{HPO}_{4} 25 \mathrm{~g} / \mathrm{l}, \mathrm{KH} 2 \mathrm{PO} 425 \mathrm{~g} / \mathrm{l}$, Threonine $20 \mathrm{~g} / 1$, Methionine $20 \mathrm{~g} / 1, \mathrm{ZnSO} 40.5 \mathrm{~g} / 1, \mathrm{MgSO}_{4} .7 \mathrm{H}_{2} \mathrm{O} 25$ $\mathrm{g} / 1, \mathrm{FeSO} 4.7 \mathrm{H}_{2} \mathrm{O} 1 \mathrm{~g} / 1$ and $\mathrm{MnSO}_{4} \cdot 5 \mathrm{H}_{2} \mathrm{O} 0.5 \mathrm{~g} / \mathrm{l}$ ), LB medium (Tryptone $10 \mathrm{~g} / 1, \mathrm{NaCl} 10 \mathrm{~g} / 1$ and Yeast 5 $\mathrm{g} / 1)$. The ddh recombinant ATCC 13032 strain was grown on LB medium and collected into test tubes with $3 \mathrm{ml}$ each into 5 test tubes which were used for inducing the chemical mutation. Then the cell cultures were incubated for $24 \mathrm{hrs}$. at $37^{\circ} \mathrm{C}$ in an orbital shaker. Centrifuge the tubes at $10000 \mathrm{xg}$ for $5 \mathrm{mins}$ and collect the pellets. These collected pellets were suspended in $3 \mathrm{ml}$ sodium citrate buffer and again centrifuge these pellets at $10000 \mathrm{xg}$ for 5 mins. The pellet is collected and resuspended into a $3 \mathrm{ml}$ buffer containing sodium citrate buffer with a PH of 4.1 and $1.2 \mathrm{ml}$ of N-nitroso-N-ethyl urea (ENU) with 100 $\mathrm{nm}$ concentration. The cultures were incubated separately for $0,5,10,15,20,25$ and $30 \mathrm{~min}$ and centrifugation has done at $10000 \mathrm{xg}$ for 5 mins after the stipulated time. The pellets were collected and suspended in $3 \mathrm{ml}$ sodium citrate buffer to wash the mutagen ENU and the resulted pellets were again suspended in the $3 \mathrm{ml}$ sodium citrate buffer to remove the traces of ENU. These pellets are incubated at $30^{\circ} \mathrm{C}$ for 3 days in the threonine and Methionine enriched seed culture media.

\section{Isolation of Auxotrophs}

The growth obtained after 3 days of incubation was inoculated in $1 \mathrm{ml}$ seed culture media without Threonine or Methionine and penicillin G is added. Incubated for $20 \mathrm{hrs}$. in $30{ }^{\circ} \mathrm{c}$ in an orbital shaker. 50 units of penicillinase were added to each tube and left for 10 minutes. $100 \mu 1$ of this growth inoculated on to seed culture media with threonine and methionine and also onto the seed culture media without threonine or methionine and incubated for 3 days at $30{ }^{\circ} \mathrm{C}$ in the orbital shaker. After the time of incubation is completed the samples were screened for Lysine production. The samples were centrifuged at $15000 \mathrm{xg}$ for $10 \mathrm{~min}$. The supernatant is collected for lysine analysis. Quantitative analysis of L Lysine was done by SDS PAGE.

\section{Optimization of Fermentation Parameters}

Different parameters like Concentration of ENU, Time of exposure of ENU, PH of the culture media, Temperature and time were tested to find the better growing conditions of the recombinant strain when treated with ENU for the high amount of production of L Lysine was tested.

In the chemical mutagenesis, we tested for different concentrations of 25, 35, 50, 75, 100 and $120 \mathrm{~nm}$ of the concentration of ENU and different times of exposure of ENU of 5,10,15,20,25 and 30 minutes to the Bacterial strain were tested at Constant Temperature, Time, and $\mathrm{Ph}$. Which are optimized conditions of wild type $C$. glutamicum for L-Lysine production. ${ }^{13}$ The recombinant strain after treating with ENU, temperature and time of incubation was kept constant and tested for different $\mathrm{pH}$ values of $6,6.5,7.0,7.5$, 8 and 8.5. After checked for different PH the ENU treated ddh recombinant cultures were tested for different temperatures of $10,25,29,30,31$ and 35 by keeping the Volume, $\mathrm{pH}$ and time of incubation constant. The $100 \mathrm{~nm}$ ENU treated recombinant C. glutamicum was tested for different time periods of incubation 24, 48,72, and $96 \mathrm{hrs}$.by keeping the $\mathrm{pH}$ at 7.5 and temperature $30{ }^{\circ} \mathrm{C}$ constant.

By checking for all the parameters we chose the best-adapted values of chemically mutated recombinant strain which had given a high amount of yield of L Lysine to culture the recombinant strain and compared with Wild TypeC. Glutamicumfor productivity of L Lysine. ${ }^{12}$

\section{Culturing the Chemical Mutagen ENU (100 nm) Treated ddh Recombinant Strain of $C$. glutamicum ATCC 13032 Under Optimized Conditions}

After optimizing the different conditions of Temperature, $\mathrm{PH}$ and time of incubation 20 min chemical mutagen ENU $(100 \mathrm{~nm})$ exposed ddh gene recombinant strain ATCC 13032 was cultured in under these conditions. The ENU treated ddh recombinant was cultured at $30^{\circ} \mathrm{C}$ of temperature, $7.5 \mathrm{pH}$ and with an incubation time of $96 \mathrm{hrs}$. was tested for the productivity of L Lysine from mutant ddh recombinant strain 
compared with normal wild type ATCC 13032 C. glutamicum mutant. $^{24}$

\section{Molecular Docking Analysis of Aspartyl $\beta$ semi aldehyde with Homoserine Dehydrogenase and 2,3 Dihydrodipicolinate Synthase}

Molecular docking was performed for Aspartyl $\beta$ semi aldehyde with Homoserine dehydrogenase and 2,3 Dihydrodipicolinate synthase to find the bonding interactions between the Protein and ligand. The amino acid sequence of Homoserine dehydrogenase enzyme of $C$. glutamicum ATCC 13032 with accession number NP 600409.1 and 2,3Dihydrodipicolinate synthase enzyme of C. glutamicum ATCC 13032 with accession number NP 601846.1 was collected and from NCBI and checked verified in the UniProt and the sequences from UniProt is used to build a protein model by Homology modeling in the SWISSMODEL Server belongs to Swiss Institute of Bioinformatics (SIB). Protein model quality built by Swiss model server analyzed through the PDBsum database. After checking the Ramachandran plot and RMSD values we choose the protein models of Homoserine dehydrogenase and 2,3 Dihydrodipicolinate synthase to dock with ligand Aspartyl $\beta$ semialdehyde in the PyREX software. Finally, the image analysis and amino acid interactions in the Protein-ligand are generated in the Discovery studio.

\section{Chemical Mutagenesis}

\section{RESULTS AND DISCUSSION}

\section{Effect of Concentration of ENU on the Recombinant Strain of C. glutamicum}

The amount of ENU used to treat plays a pivotal role in causing Mutagenesis in the bacterial species. The recombinant $C$. glutamicum showed high productivity of L Lysine of $23.28 \mathrm{~g} / 1$ of yield by keeping the temperature, time of incubation, and PH constant at $100 \mathrm{Nm}$ concentration of ENU. Optimized conditions to grow the wild type $C$. glutamicum ATCC 13032 strain for maximum yield of L Lysine of $96 \mathrm{hrs}$. time of incubation, $30 \mathrm{C}$ of temperature and PH 7.5. Kept constant by checking the yield for 25,35,50,75, 100 and $120 \mathrm{~nm}$ of concentration produced $20.66 \mathrm{~g} / 1,20.11 \mathrm{~g} / 1,21.05 \mathrm{~g} / 1,22.10 \mathrm{~g} / 1,23.28 \mathrm{~g} / \mathrm{l}$ and $18.17 \mathrm{~g} / \mathrm{l}$ of L Lysine respectively. We got high productivity of L Lysine at $100 \mathrm{~nm}$ concentration of ENU $23.28 \mathrm{~g} / 1$ for Auxotrophic ddh recombinant mutant and a high yield of $16.23 \mathrm{~g} / 1$ for Auxotrophic mutant of wild type C. glutamicum when compared to $35 \mathrm{~nm}, 50 \mathrm{~nm}, 75 \mathrm{~nm}$ concentrations of ENU.

Table-1: Table for L Lysine Production at Different ENU Concentrations

\begin{tabular}{c|c|c|c|c|c|c}
\hline S.No. & $\begin{array}{c}\text { Time of } \\
\text { Incubation } \\
\text { (Hours) }\end{array}$ & Temperature $\left(0^{\circ} \mathrm{C}\right)$ & $\begin{array}{c}\text { The Concentration } \\
\text { of ENU Treated. }\end{array}$ & $\mathrm{pH}$ & $\begin{array}{c}\text { L-Lysine } \\
\text { Concentration } \\
\text { Auxotrophic } \\
\text { Wild Type }\end{array}$ & $\begin{array}{c}\text { L-Lysine } \\
\text { Concentration } \\
\text { Auxotrophic } \\
\text { Mutant }\end{array}$ \\
\hline 1 & 96 & 30 & 25 & 7.5 & 13.26 & 20.11 \\
\hline 2 & 96 & 30 & 35 & 7.5 & 13.50 & 20.66 \\
\hline 3 & 96 & 30 & 50 & 7.5 & 14.40 & 21.05 \\
\hline 4 & 96 & 30 & 75 & 7.5 & 15.80 & 22.10 \\
\hline 5 & 96 & 30.0 & 100 & 7.5 & 16.23 & 23.28 \\
\hline 6 & 96 & 30.0 & 120 & 7.5 & 14.99 & 18.17 \\
\hline
\end{tabular}

The amounts of L Lysine produced shown increased trend from $25 \mathrm{~nm}$ concentration up to a maximum amount of L Lysine achieved at $100 \mathrm{~nm}$ concentration of ENU $23.28 \mathrm{~g} / 1$ which is increased from $20.66 \mathrm{~g} / 1$ represented in table 1 and plotted in the Fig 1 by taking L Lysine concentration on Y-axis and Concentration of ENU on X-axis. The pattern of increase of L Lysine production shown illustrated in Fig.-1.

\section{The Effect of Time of Exposure of ENU on Recombinant $C$. glutamicum ATCC 13032}

The ENU treated recombinant C. glutamicum showed maximum yield of L Lysine of $24.02 \mathrm{~g} / 1$ for 20 mins of exposure of chemical mutagen at $100 \mathrm{~nm}$ of concentration were compared to different times of exposure chemical mutagen at $100 \mathrm{~nm}$ concentration for 5, 10, 15,25 and 30 mins. The effect of ENU on the L Lysine is recorded maximum at 20 min of exposure before washing with citrate buffer in the process of creating the Auxotrophic mutant ${ }^{4}$ from the recombinant ATCC 13032. The increased productivity of L 
RASĀYAN J. Chem.

Vol. 13 | No. 2 |1245-1261| April - June | 2020

Lysine Yield by taking the time of exposure of ENU is represented in the Fig 2 by plotting the Fig between Time of exposure of ENU on X-axis and Concentration of L Lysine on Y axis from the values of table 2 got for different times of exposure of ENU by keeping Time of incubation $96 \mathrm{hrs}$., Temperature 30 $\mathrm{C}$ and $100 \mathrm{~nm}$ Concentration of ENU and PH of 7.5 Constant. The trend of the Fig increased from 5 mins of exposure till 20 mins of exposure recorded $20.22 \mathrm{~g} / 1,22.67 \mathrm{~g} / 1,23.17 \mathrm{~g} / 1$ and $24.02 \mathrm{~g} / 1$ for 5 mins, 10 mins, 15 mins and 20 mins of exposure to ENU respectively. The maximum yield of L Lysine achieved by the Auxotrophic mutant of ddh recombinant is $24.02 \mathrm{~g} / 1$ and for Auxotrophic mutant of the wild type strain is $16.48 \mathrm{~g} / \mathrm{l}$ at $20 \mathrm{mins}$ of exposure of ENU. After 25 mins of exposure decreased the amount of $\mathrm{L}$ Lysine yield to $22.23 \mathrm{~g} / \mathrm{l}$ and at $30 \mathrm{~min}$ of exposure, it was $21.56 \mathrm{~g} / \mathrm{l}$.

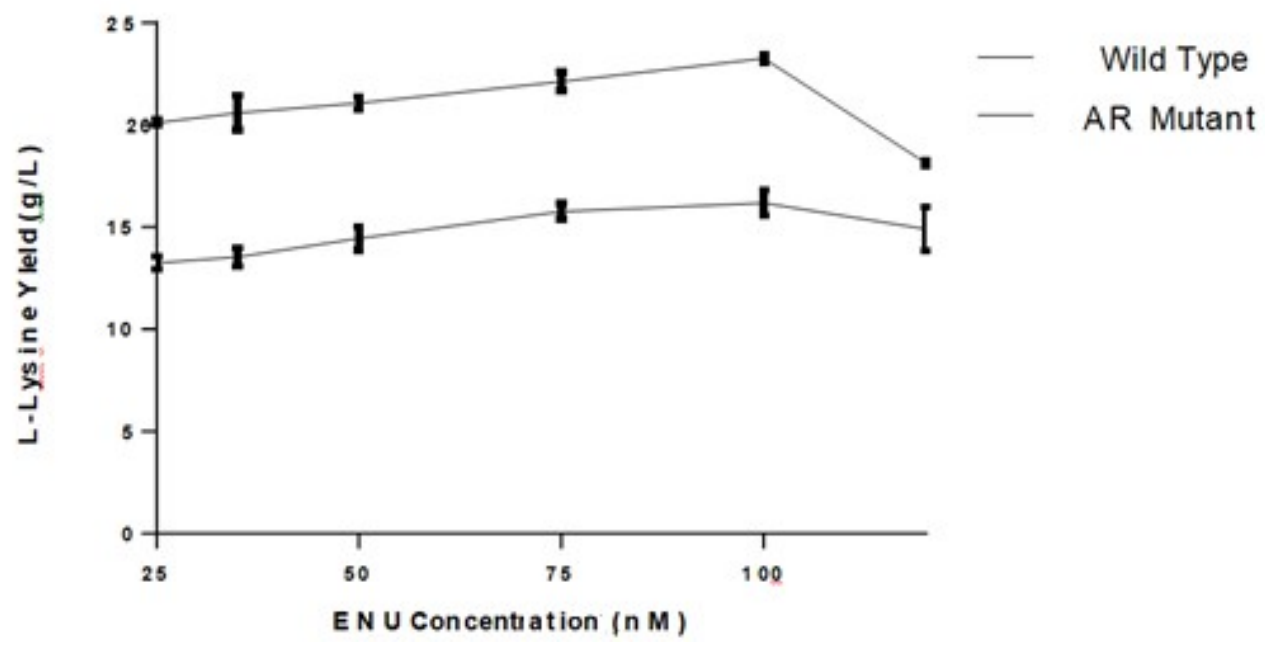

Fig.-2: A Plot between Concentration of ENU exposed Vs Concentration of L Lysine produced. The L-Lysine concentration showed an increased pattern with an increase in the concentration from $25 \mathrm{~nm}$ till $100 \mathrm{~nm}$ with a maximum yield of $23.28 \mathrm{~g} / \mathrm{l}$ and decreased at $125 \mathrm{~nm}$ concentration at constant values, time of Incubation $96 \mathrm{hrs}$., Temperature $30^{\circ} \mathrm{C}$ and $\mathrm{PH} 7.5$.

The amounts of L Lysine produced shown increased trend from $25 \mathrm{~nm}$ concentration up to a maximum amount of L Lysine achieved at $100 \mathrm{~nm}$ concentration of ENU $23.28 \mathrm{~g} / 1$ which is increased from $20.66 \mathrm{~g} / 1$ represented in Table-1 and plotted in the Fig.-1 by taking L Lysine concentration on Y-axis and Concentration of ENU on X-axis. The pattern of increase of L Lysine production shown illustrated in Fig.-2.

\section{The Effect of Time of Exposure of ENU on Recombinant $C$. glutamicum ATCC 13032}

The ENU treated recombinant $C$. glutamicum showed maximum yield of L Lysine of $24.02 \mathrm{~g} / 1$ for 20 mins of exposure of chemical mutagen at $100 \mathrm{~nm}$ of concentration were compared to different times of exposure chemical mutagen at $100 \mathrm{~nm}$ concentration for 5, 10, 15,25 and 30 mins. The effect of ENU on the L Lysine is recorded maximum at 20 min of exposure before washing with citrate buffer in the process of creating the Auxotrophic mutant ${ }^{4}$ from the recombinant ATCC 13032. The increased productivity of L Lysine Yield by taking the time of exposure of ENU is represented in the Fig.-2 by plotting the Figure between Time of exposure of ENU on X-axis and Concentration of L Lysine on Y axis from the values of Table-2 got for different times of exposure of ENU by keeping Time of incubation 96 hrs., Temperature $30 \mathrm{C}$ and $100 \mathrm{~nm}$ Concentration of ENU and PH of 7.5 Constant. The trend of the Fig increased from 5 mins of exposure till 20 mins of the exposure recorded $20.22 \mathrm{~g} / 1,22.67 \mathrm{~g} / \mathrm{l}, 23.17 \mathrm{~g} / \mathrm{l}$ and $24.02 \mathrm{~g} / \mathrm{l}$ for 5 mins, 10 mins, $15 \mathrm{mins}$ and 20 mins of exposure to ENU respectively. The maximum yield of L Lysine achieved by the Auxotrophic mutant of ddh recombinant is $24.02 \mathrm{~g} / \mathrm{l}$ and for Auxotrophic mutant of the wild type strain is $16.48 \mathrm{~g} / 1$ at 20 mins of exposure of ENU. After 25 mins of exposure decreased the amount of L Lysine yield to $22.23 \mathrm{~g} / \mathrm{l}$ and at $30 \mathrm{~min}$ of exposure, it was $21.56 \mathrm{~g} / \mathrm{l}$. 
RASĀYAN J. Chem.

Vol. 13 | No. 2 |1245-1261| April - June | 2020

Table-2: Table for L Lysine Production at Different Times of Exposure of ENU to ddh Recombinant Strain.

\begin{tabular}{c|c|c|c|c|c|c|c}
\hline S.No. & $\begin{array}{c}\text { Time of } \\
\text { Incubation } \\
\text { (hours) }\end{array}$ & $\begin{array}{c}\text { Temperature } \\
\left(0^{0} \mathrm{c}\right)\end{array}$ & $\begin{array}{c}\text { Time of } \\
\text { exposure } \\
\text { of ENU } \\
\text { In Mins. }\end{array}$ & $\begin{array}{c}\text { Concentration } \\
\text { of ENU in } \\
\text { Nanomolar }\end{array}$ & $\mathrm{pH}$ & $\begin{array}{c}\text { L-Lysine } \\
\text { concentration } \\
\text { Auxotrophic Wild } \\
\text { Type }\end{array}$ & $\begin{array}{c}\text { L-Lysine } \\
\text { concentration } \\
\text { Auxotrophic } \\
\text { Mutant }\end{array}$ \\
\hline 1 & 96 & 30 & 5 & 100 & 7.5 & 13.05 & 20.22 \\
\hline 2 & 96 & 30 & 10 & 100 & 7.5 & 14.78 & 22.67 \\
\hline 3 & 96 & 30 & 15 & 100 & 7.5 & 15.23 & 23.17 \\
\hline 4 & 96 & 30 & 20 & 100 & 7.5 & 16.48 & 24.02 \\
\hline 5 & 96 & 30 & 25 & 100 & 7.5 & 15.54 & 22.23 \\
\hline 6 & 96 & 30 & 30 & 100 & 7.5 & 14.23 & 21.56 \\
\hline
\end{tabular}

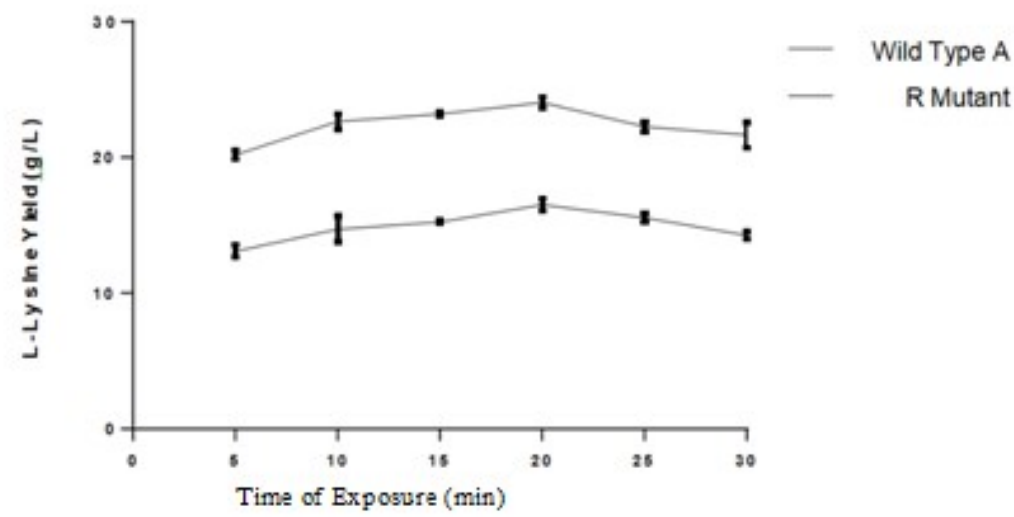

Fig.-3: A Plot between Time of Exposure of $100 \mathrm{nM}$ ENU and L. LysineYield. The L Lysine concentration showed an increased pattern with an increase in the Time of exposure of ENU from 5 mins to $20 \mathrm{mins}$. with a maximum yield of $24.02 \mathrm{~g} / \mathrm{l}$ and $16.48 \mathrm{~g} / \mathrm{l}$ for Recombinant and wild type mutants respectively and decreased at 25 mins. of ENU exposure at a constant time of Incubation 96 hrs., Temperature $30^{\circ} \mathrm{C}$ and PH 7.5.

\section{Isolation of Auxotrophic Mutant}

After three days of incubation, the strains that show growth in the presence of Methionine or Threonine or the presence of both the amino acids were considered as auxotrophic mutants and were isolated and cultured. Due to a lack of homoserine dehydrogenase, the mutant strains utilize the Threonine and methionine supplemented in the media. The auxotrophic mutants require more quantity of threonine and methionine in their media signifies the lack of Homoserine pathway that could occur in the normal strains of both Wild types as well as ddh recombinant varieties of C. glutamicum ATCC 13032. These auxotrophic mutants were used further to know the optimized conditions of $\mathrm{PH}$, Temperature and time of incubation. $^{10}$

The Chemical mutagen had shown its maximum activity at $100 \mathrm{~nm}$ by blocking the Homoserine dehydrogenase a key enzyme in the production of Threonine and methionine. The ENU caused mutation in the Homoserine dehydrogenase gene which generally combines with Aspartyl B Semi aldehyde to produce the homoserine. This blockage in the Homoserine pathway favors the DAP pathway by combining with 2,3, Dihydrodipicolinate synthase produced 2,3, Dihydrodipicolinate which reduces to 2,6 , a dicarboxylic acid.

Optimization of PH, Temperature and Time of Incubation for Chemical mutagen ENU treated $d d h$ recombinant strain of $C$. glutamicum ATCC 13032

Effect of pH on the Recombinant strain of $C$. glutamicum

The ENU concentration used to mutate the recombinant strain is $100 \mathrm{Nm}$ which was an optimized condition for high productivity of L Lysine was used which was treated on Recombinant strain for 20 
RASĀYAN J. Chem.

Vol. 13 | No. 2 |1245-1261| April - June | 2020

mins. The recombinant strain has shown maximum lysine productivity of $22.16 \mathrm{~g} / \mathrm{l}$ at $7.5 \mathrm{pHs}$ when compared to ENU mutated wild type strain ATCC 13032 at the same 7.5 pHs. The Productivity of 1 lysine is increased considerably in the recombinant strain for all the Ph values when compared with wild type strain. But both the strains had shown maximum productivity at $7.5 \mathrm{pH}$.

The trend of production of L Lysine increased from $\mathrm{pH} 6.0$ to 7.5 and shown decreased productivity for $\mathrm{pH} 8$ and $\mathrm{PH}$ 8.5. The L Lysine yield recorded maximum at $\mathrm{pH} 7.5$ with an L Lysine concentration of $24.32 \mathrm{~g} / 1.16 .50 \mathrm{~g} / \mathrm{l}, 18.17 \mathrm{~g} / 1,22.16 \mathrm{~g} / 1,24.32 \mathrm{~g} / 1,19.17 \mathrm{~g} / 1$ and $17.29 \mathrm{~g} / 1$ of L Lysine yield was reported for 6.0,6.5 7.0, 7.5, 8.0 and $8.5 \mathrm{pH}$ values respectively represented in the Table-3. The L Lysine yield recorded maximum at $7.5 \mathrm{pH}$ with $24.32 \mathrm{~g} / 1$ for Auxotrophic recombinant mutant and $17.02 \mathrm{~g} / \mathrm{l}$ for an auxotrophic mutant of wild type $\mathrm{C}$. glutamicum. The Fig was plotted by taking $\mathrm{PH}$ values on the $\mathrm{X}$-axis and Yield on the Y-axis and illustrated the trend of increase in the productivity of L Lysine in Fig.-3.

Table-3: Table for L Lysine Production at Different Times of Exposure of ENU to ddh Recombinant Strain.

\begin{tabular}{c|c|c|c|c|c}
\hline S.No. & $\begin{array}{c}\text { Time of } \\
\text { Incubation } \\
\text { (hours) }\end{array}$ & $\begin{array}{c}\text { Temperature } \\
\left(0^{0} \mathrm{c}\right)\end{array}$ & $\mathrm{pH}$ & $\begin{array}{c}\text { L-Lysine } \\
\text { concentration } \\
\text { Auxotrophic Wild } \\
\text { Type }\end{array}$ & $\begin{array}{c}\text { L-Lysine } \\
\text { concentration } \\
\text { Auxotrophic } \\
\text { Mutant }\end{array}$ \\
\hline 1 & 96 & 30 & 6.0 & 14.78 & 16.50 \\
\hline 2 & 96 & 30 & 6.5 & 15.02 & 18.17 \\
\hline 3 & 96 & 30 & 7.0 & 16.35 & 22.16 \\
\hline 4 & 96 & 30 & 7.5 & 17.02 & 24.32 \\
\hline 5 & 96 & 30 & 8.0 & 16.21 & 19.17 \\
\hline 6 & 96 & 30 & 8.5 & 13.23 & 17.29 \\
\hline
\end{tabular}

The $\mathrm{pH}$ showed its impact on media utilization and glucose consumption by maximum uptake of glucose at $7.5 \mathrm{pH}$ had supported the increased participation of the C. glutamicum in the Dap pathway for the LLysine synthesis. The $\mathrm{pH}$ had shown its impact on the fluidity of bacterial cell wall and Plasma membrane of the C. glutamicum at 7.5 which helped in glucose consumption.

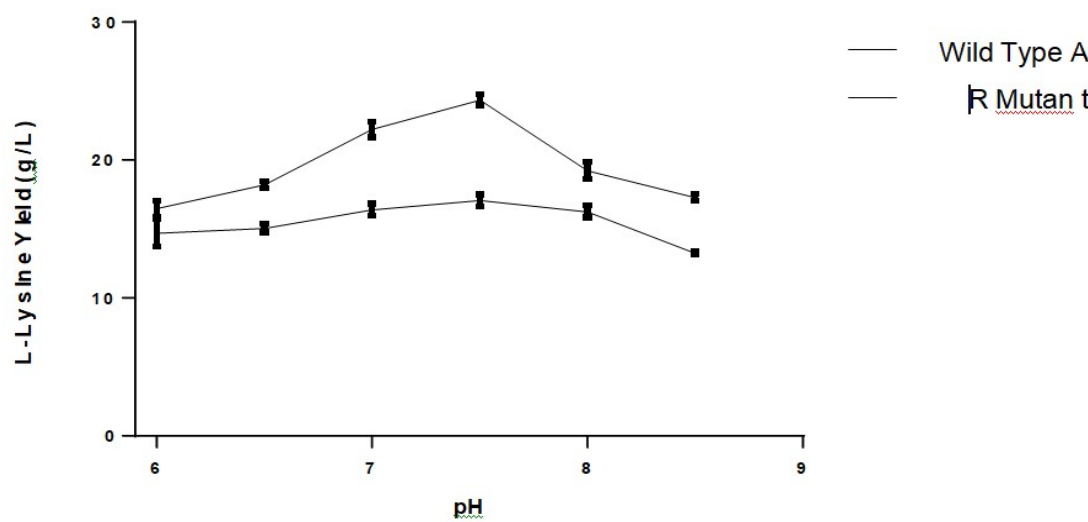

Fig.-4: Plot between a $\mathrm{pH}$ of the Media and L Lysine Yield. The L Lysine concentration showed increased pattern with increase with the increase in value of $\mathrm{pH}$, from 6.0 to 7.5 reached the maximum yield of $24.32 \mathrm{~g} / \mathrm{l}$ L-Lysine and decreased for further increase in the PH by keeping time of Incubation for $96 \mathrm{hrs}$., Temperature $30^{\circ} \mathrm{C}$ constant after treating with ENU $(100 \mathrm{~nm})$ with $20 \mathrm{mins}$ of exposure before washing.

Effect of Temperature on the Recombinant Strain of $C$. glutamicum

Here the strain treated with $100 \mathrm{Nm}$ concentration of ENU which was exposed to ENU for 20 mins was tested. The incubation was kept for different temperatures and $\mathrm{pH}$ of 7.5 and time of incubation $96 \mathrm{hrs}$. 
RASĀYAN J. Chem.

Vol. 13 | No. 2 |1245-1261| April - June | 2020

was kept constant. The recombinant strain showed an increased productivity of L Lysine with the maximum amount of L Lysine was $24.20 \mathrm{~g} / 1$ at $30 \mathrm{C}$ of temperature. All the recombinant strains showed an increased pattern in the L Lysine production till $30 \mathrm{C}$ and productivity decreased for $31 \mathrm{C}$ and $32 \mathrm{C}$ of temperature. L Lysine yield of $17.11 \mathrm{~g} / 1,19.52 \mathrm{~g} / 1,22.78 \mathrm{~g} / 1,24.20 \mathrm{~g} / 1,22.16 \mathrm{~g} / 1$ and $18.17 \mathrm{~g} / \mathrm{l}$ for temperatures $27.0^{\circ} \mathrm{C}, 28.0^{\circ} \mathrm{C}, 29.0^{\circ} \mathrm{C}, 30.0^{\circ} \mathrm{C}, 31.0^{\circ} \mathrm{C}$ and $32.0^{\circ} \mathrm{C}$ respectively was reported is represented in the Table-4. The Auxotrophic mutant of ddh recombinant strain had shown the maximum L Lysine productivity of $24.20 \mathrm{~g} / 1$ and wild type auxotrophic mutant shown 18.13 maximum L Lysine yield at $30^{\circ} \mathrm{C}$. The trend for the increase in the productivity of L Lysine is illustrated in Fig. -4 by taking the $\mathrm{PH}$ on the $\mathrm{X}$-axis and L Lysine Yield on Y axis.

Table-4: Table for L Lysine Production at Different Temperatures of ENU treated ddh Recombinant C.glutamicum.

\begin{tabular}{c|c|c|c|c|c}
\hline S.No. & $\begin{array}{c}\text { Time of } \\
\text { Incubation } \\
\text { (hours) }\end{array}$ & $\begin{array}{c}\text { Temperature } \\
\left(0^{0} \mathrm{c}\right)\end{array}$ & $\mathrm{pH}$ & $\begin{array}{c}\text { L-Lysine } \\
\text { concentration } \\
\text { Auxotrophic Wild } \\
\text { Type }\end{array}$ & $\begin{array}{c}\text { L-Lysine } \\
\text { concentration } \\
\text { Auxotrophic } \\
\text { Mutant }\end{array}$ \\
\hline 1 & 96 & 27 & 7.5 & 15.23 & 17.11 \\
\hline 2 & 96 & 28 & 7.5 & 16.07 & 19.52 \\
\hline 3 & 96 & 29 & 7.5 & 17.45 & 22.78 \\
\hline 4 & 96 & 30 & 7.5 & 18.13 & 24.2 \\
\hline 5 & 96 & 31 & 7.5 & 17.66 & 22.16 \\
\hline 6 & 96 & 32 & 7.5 & 16.52 & 18.17 \\
\hline
\end{tabular}

The L Lysine concentration showed an increased pattern with an increase in temperature, from $27{ }^{\circ} \mathrm{C}$ to $30^{\circ} \mathrm{C}$ reached the maximum yield of $24.20 \mathrm{~g} / 1$ and $18.13 \mathrm{~g} / 1 \mathrm{~L}-$ Lysine respectively for Auxotrophic mutants of ddh recombinant and wild type and decreased for a further increase in the temp. by keeping the time of Incubation for 96 hrs., pH 7.5 constant after treating with ENU $(100 \mathrm{~nm})$ with 20 mins of exposure (Fig.-4).

The temperature had shown its significant effect on the rate of metabolism favoring the enzymes and substrates that participates in the synthesis of Amino acids. The temperature of $30{ }^{\circ} \mathrm{C}$ had favored the enzyme-substrate complex formations and showed its impact on the increased rate of reactions by reducing the activation energies of catalytic enzymes that were involved in the L Lysine pathway by keeping the Time, Volume and $\mathrm{pH}$ are constant.

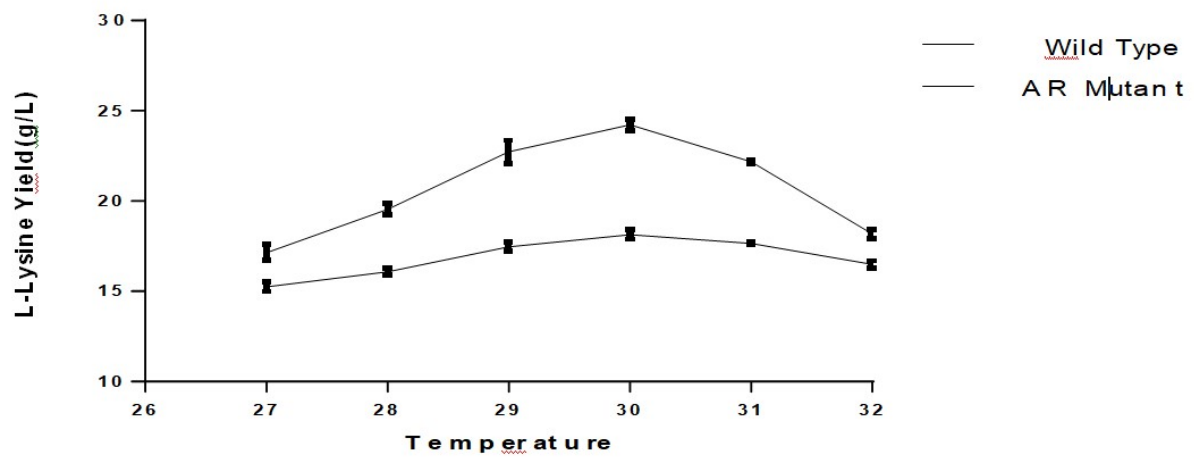

Fig.-5: A Plot between Changes in the Temperature vs L-Lysine Yield

\section{Effect of Time of incubation on ENU treated recombinant strain of $\boldsymbol{C}$. glutamicum}

The recombinant strain has shown maximum productivity of $24.16 \mathrm{~g} / 1$ after $72 \mathrm{hrs}$. and also shown increased productivity when compared with ENU mutated wild type strain. The time of incubation is 96 
RASĀYAN J. Chem.

Vol. 13 | No. 2 |1245-1261| April - June | 2020

hrs. for wild type strain which is also the same for both Recombinant and ENU treated Recombinant strains of C. glutamicum ATCC13032. The Time of incubation signifies the growth kinetics of C. glutamicum. Further incubating the strain showed the decrease in the quantity of L lysine production due to the strain entering into death phase between 96 to $120 \mathrm{hrs}$. of incubation.

The L Lysine productivity increased while the time of incubation is being increased. The L Lysine productivity for $12 \mathrm{hrs} ., 24 \mathrm{hrs} ., 48 \mathrm{hrs} ., \quad 72 \mathrm{hrs}$., $96 \mathrm{hrs}$., and $120 \mathrm{hrs}$. was $10.23 \mathrm{~g} / 1,13.21 \mathrm{~g} / 1,17.16 \mathrm{~g} / \mathrm{l}$, $18.68, \mathrm{~g} / 1,24.16 \mathrm{~g} / 1$ and $18.17 \mathrm{~g} / 1$ respectively represented in the Table-5 and plotted in Fig.-5 by taking Time of incubation on the $\mathrm{X}$-axis and L Lysine yield on the $\mathrm{Y}$-axis. The trend of the time of incubation increased from $12 \mathrm{hrs}$. to $96 \mathrm{hrs}$. reached the maximum L Lysine concentration of $24.16 \mathrm{~g} / \mathrm{l}$ for Auxotrophic recombinant mutant and $17.98 \mathrm{~g} / 1$ for Auxotrophic mutant of L Lysine further decreased to $18.17 \mathrm{~g} / \mathrm{l}$ and 15.23 for Recombinant and Wild type mutants respectively at $120 \mathrm{hrs}$. of incubation.

Table-5: Table for L Lysine Production at Different Times of Incubation of ENU Treated ddh Recombinant

\begin{tabular}{c|c|c|c|c|c}
\hline \multicolumn{6}{c}{ C.glutamicum } \\
\hline S.No. & $\begin{array}{c}\text { Time of } \\
\text { Incubation } \\
\text { (hours) }\end{array}$ & $\begin{array}{c}\text { Temperature } \\
\left(0^{0} \mathrm{C}\right)\end{array}$ & $\mathrm{pH}$ & $\begin{array}{c}\text { L-Lysine } \\
\text { Concentration } \\
\text { Auxotrophic Wild } \\
\text { Type }\end{array}$ & $\begin{array}{c}\text { L-Lysine } \\
\text { Concentration } \\
\text { Auxotrophic } \\
\text { Mutant }\end{array}$ \\
\hline 1 & 12 & 30 & 7.5 & 14.56 & 15.78 \\
\hline 2 & 24 & 30 & 7.5 & 15.11 & 16.43 \\
\hline 3 & 36 & 30 & 7.5 & 16.32 & 17.16 \\
\hline 4 & 48 & 30 & 7.5 & 16.43 & 18.68 \\
\hline 5 & 72 & 30 & 7.5 & 17.98 & 24.16 \\
\hline 6 & 96 & 30 & 7.5 & 15.23 & 18.17 \\
\hline
\end{tabular}

The L Lysine concentration showed an increased pattern with an increase with the increase in time of incubation, from $12 \mathrm{hrs}$. to $96 \mathrm{hrs}$. reached the maximum yield of $24.16 \mathrm{~L}$ and $17.98 \mathrm{~g} / \mathrm{l} \mathrm{Lysine}$ for Auxotrophic recombinant mutant and auxotrophic wild type mutant respectively and decreased for a further increase in the time by keeping temperature $30^{\circ} \mathrm{C}$., $\mathrm{PH} 7.5$ constant after treating with ENU(100nm) with 20 mins of exposure before washing.

The Corynebacterium glutamicum had entered the stationary phase after the $96 \mathrm{hrs}$. of incubation is the reason for and production of L Lysine increased substantially after the logarithmic phase and reached the maximum amount of L Lysine production between $72 \mathrm{hrs}$. to $96 \mathrm{hrs}$. of incubation.

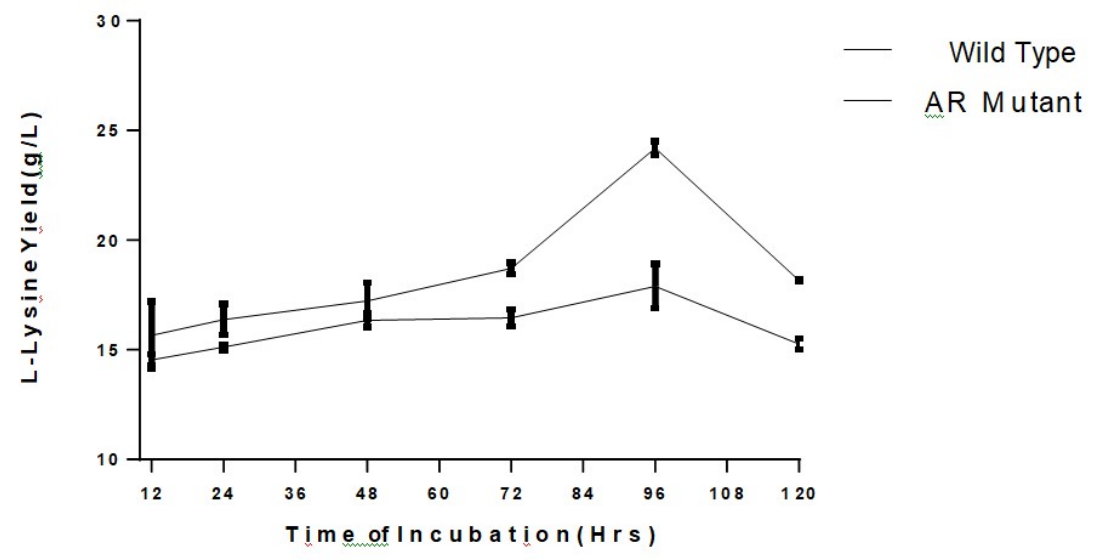

Fig.-6: A Plot between Time of Incubation for $d d h$ gene Recombinant $C$. glutamicum and L Lysine yield.

Comparative Analysis of Maximum Yields of $L$ Lysine for Auxotrophic ddh Recombinant Mutant and Auxotrophic Wild Type Mutant at Optimized Conditions

By optimizing the growth of ENU treated ddh Recombinant ATCC 13032 strain of C. glutamicum we got 
RASĀYAN J. Chem.

Vol. 13 | No. 2 |1245-1261| April - June | 2020

$23.28 \mathrm{~g} / 1$ of L Lysine and $16.2 \mathrm{~g} / \mathrm{l}$ of L lysine for wild type auxotrophic mutant for $100 \mathrm{~nm}$ concentration of ENU. By treating the ENU $(100 \mathrm{~nm})$ concentration for 20 minutes we got the better yield of $24.02 \mathrm{~g} / 1$ for ddh recombinant strain and $16.48 \mathrm{~g} / \mathrm{l}$ for the Wild type. After isolating the Auxotrophic mutant for Threonine and Methionine after exposing to ENU $(100 \mathrm{~nm})$ for 20 mins of time of exposure of ENU before washing with Citrate buffer was checked for different $\mathrm{pH}$, different Temperatures and for different times of incubation for ddh gene recombinant ATCC auxotrophic mutant of C. glutamicum and wild type auxotrophic mutant. we got a better yield of L Lysine of $24.32 \mathrm{~g} / \mathrm{L}$ for the ddh Recombinant auxotrophic mutant and $17.02 \mathrm{~g} / 1$ for wild type auxotrophic mutant at $7.5 \mathrm{pH}$. We got a better yield of $24.20 \mathrm{~g} / 1 \mathrm{of}$. Lysine for Auxotrophic mutant of ddh recombinant C. glutamicum and $18.13 \mathrm{~g} / \mathrm{l}$ for wild type auxotrophic mutant at $30^{\circ} \mathrm{C}$ of temperature and high productivity of $24.16 \mathrm{~g} / 1$ and $17.98 \mathrm{~g} / 1 \mathrm{of} \mathrm{L}$ Lysine respectively after $96 \mathrm{hrs}$. of time of Incubation (Fig.-6). Hence the best optimizing conditions for ENU treated ddh Recombinant mutant strain of Corynebacterium glutamicum shown for high yield of L Lysine at the $100 \mathrm{~nm}$ concentration of ENU with an exposure time of 20 mins created an Auxotroph which shows a better yield of $\mathrm{L}$ Lysine at $7.5 \mathrm{pH}, 30^{\circ} \mathrm{C}$ of temperature and $96 \mathrm{hrs}$. of Incubation. The Optimized Parameters and amount of L Lysine Produced for Recombinant mutant and quantity of L Lysine produced by wild type auxotrophic mutant at the same conditions of recombinant strain was tabulated in Table- 6 .

Table-6: Table for L Lysine production for ddh recombinant mutant and wild type mutant at the optimized parameters of ddh recombinant mutant.

\begin{tabular}{c|c|c|c}
\hline S. No. & Optimized Parameters & L Lysine in Wt.mutant $(\mathrm{g} / \mathrm{l})$ & $\begin{array}{c}\text { L Lysine in AR } \\
\text { Mutant }(\mathrm{g} / \mathrm{l})\end{array}$ \\
\hline 1. & Conc. Of ENU $(100 \mathrm{~nm})$ & 16.12 & 23.28 \\
\hline 2. & Time of exposure $(20 \mathrm{~min})$. & 16.48 & 24.02 \\
\hline 3. & PH $(7.5)$ & 17.02 & 24.32 \\
\hline 4. & Temperature $\left(30^{\circ} \mathrm{C}\right)$ & 18.13 & 24.20 \\
\hline 5. & Time of incubation $96 \mathrm{hrs}$. & 17.98 & 24.16 \\
\hline
\end{tabular}

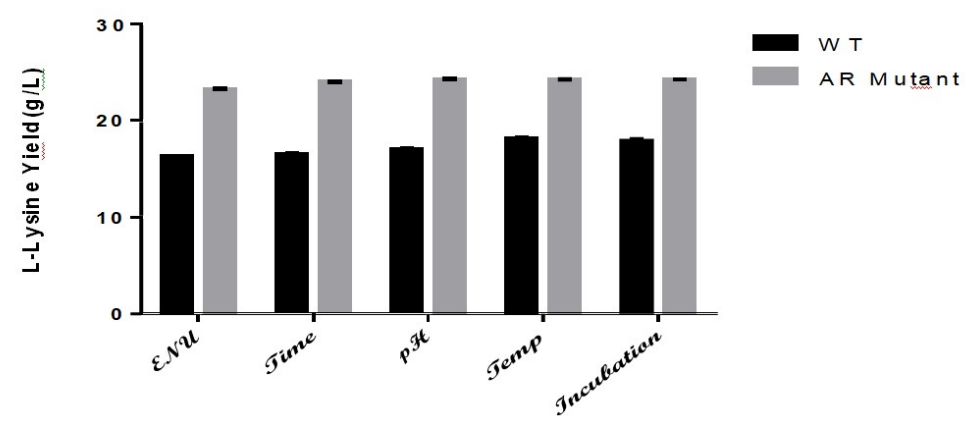

Fig.-7: Maximum Yield of L Lysine for Auxotrophic Wild Type Mutant (WT) and auxotrophic ddh recombinant mutant (AR Mutant) based on Optimized parameters of Recombinant strain.

\section{Molecular docking analysis of Aspartyl $\beta$ Semi Aldehyde Ligand With Homoserine Dehydrogenase Protein}

Homology model is developed in the SWISS-MODEL server for the amino acid sequence collected from UniProt. ${ }^{37}$ The Protein model built in the Swiss model ${ }^{36}$ collected in the .pdb format. The protein model is further analyzed in PDBsum ${ }^{37}$ database to check the protein quality for docking. The Ramachandran plot had shown nearly $91.5 \%$ of residues in the favorable regions and RMS distance from planarity is around 2 signified good protein quality. The ligand of aspartyl semi aldehyde collected from PubChem is used to dock in the PyREX ${ }^{35}$ software with the Modeled Homoserine dehydrogenase protein. The ligand Aspartyl $\beta$ semi aldehyde had shown its interaction with glycine GLY (151) with a hydrogen bond and also a carbon-hydrogen bond with glycine GLY (288). Proline PRO (B: 287) Alanine ALA (B:289), tyrosine TYR (B: 178,155), Glycine GLY (B:268, 151), Asparagine ASN (B:270) and Leucine LEU (B: 154) are the interacting amino acids with the ligand in Homoserine dehydrogenase. Homoserine 
RASĀYAN J. Chem.

Vol. 13 | No. 2 |1245-1261| April - June | 2020

dehydrogenase enzyme is with one conventional hydrogen bond. The Homoserine dehydrogenase showed good interaction with the ligand Aspartyl $\beta$ semi aldehyde with a binding energy of -5.2 Kcal (Fig.-7). Homoserine dehydrogenase had nine interacting amino acids is the reason for having high binding energy even though having only a hydrogen bond and a Carbon-hydrogen bond ${ }^{36}$.

\section{Molecular Docking Analysis of Aspartyl ß Semi Aldehyde Ligand With 2,3Dihydrodipicolinate Synthase}

Homology model is developed in the SWISS-MODEL server for the amino acid sequence 2,3 Dihydrodipicolinate synthase collected from UniProt. The Protein model built in the Swiss model collected in the .pdb format. The protein model is further analyzed in the PDBsum database to check the protein quality for docking. The Ramachandran plot had shown nearly $90.05 \%$ of residues in the favorable regions and RMS distance from planarity is between 1.5 to a signifying good quality of modeled protein. The ligand of aspartyl semi aldehyde collected from PubChem is used to dock in the PyREX software with the Modeled 2,3 Dihydrodipicolinate synthase protein. The ligand Aspartyl $\beta$ semi aldehyde had shown its interaction with Leucine (B:206), Serine (B:261), Aspartate ASP (B:205) and Isoleucine (B:257) with a conventional hydrogen bond. 2,3, Dihydrodipicolinate synthase is with 4 conventional hydrogen bonds. Leucine LEU (B:206), Aspartate ASP (B:205), Serine SER (B:261) and Isoleucine ILE (B:257) were the interacting amino acids of 2,3, Dihydrodipicolinate synthase. The 2,3Dihydrodipicolinate synthase showed good interaction with the ligand Aspartyl semi aldehyde with binding energy of $-4.4 \mathrm{Kcal}$ (Fig.-8). Even though it had fewer amino acid interactions but due to the presence of 4 hydrogen bonds it can able to show considerable binding with the Ligand ${ }^{37}$.
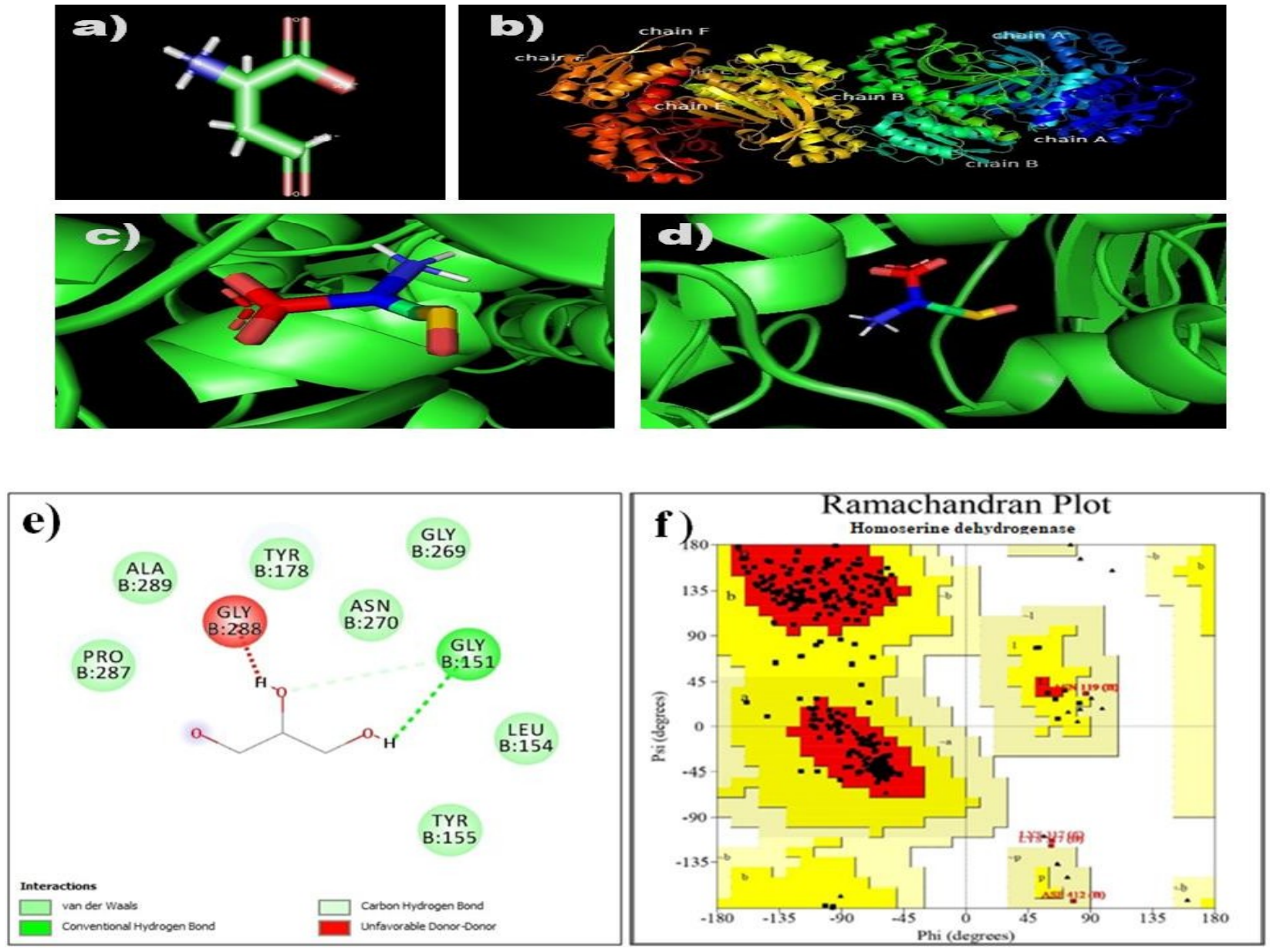
RASĀYAN J. Chem.

Vol. 13 | No. 2 |1245-1261| April - June | 2020

RMS distances from planarity

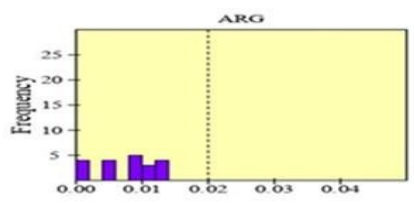

homoserine dehydrogenase
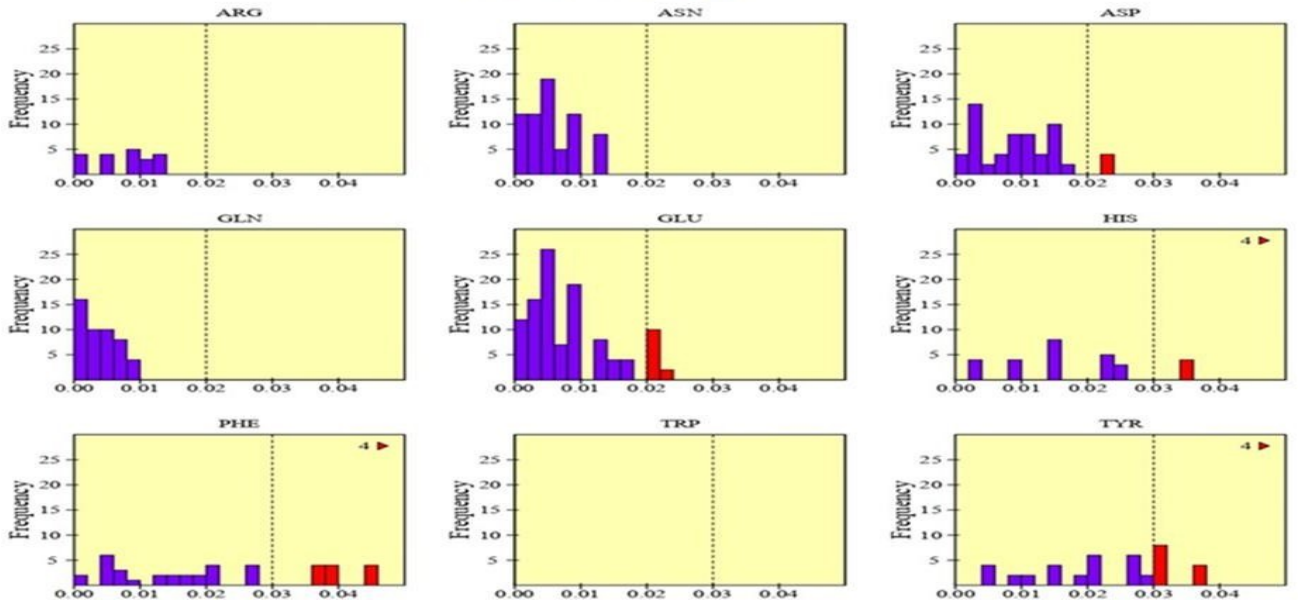

Fig.-8: (a) Ligand Aspartyl $\beta$ semialdehyde, (b) Protein Homoserine dehydrogenase (c and d) Protein-ligand interaction (Docking in Pyrex), (e) lid plot analysis (PDBsum) of Ligand Aspartyl $\beta$ semi aldehyde with Protein Homoserine dehydrogenase: GLY (151), H-bond and C-H bond with GLY (288). PRO (B: 287), ALA (B:289), TYR

(B: 178,155), GLY (B:268, 151), ASN (B:270) and LEU (B: 154) are the interacting amino acids in protein Homoserine dehydrogenase with the ligand Aspartyl $\beta$ semi aldehyde, (f) Ramachandran plot for HSD with $91.5 \%$ favored regions,(g) RMSD value of HSD between 1.5 to 2.0 for HSD signifying the good quality of Protein to be docked with the ligand.

Table-7: Ramachandran Plot Statistics Representing the Quality of Proteins Used for Modeling

\begin{tabular}{|c|c|c|c|c|c|}
\hline S.No. & Plot Statistics & \multicolumn{2}{|c|}{ Homoserine Dehydrogenase } & \multicolumn{2}{|c|}{ 2,3 Dihydrodipicolinate Synthase } \\
\hline 1 & $\begin{array}{l}\text { Residues in most favored regions } \\
{[A, B, L]}\end{array}$ & 1124 & $91.5 \%$ & 447 & $90.5 \%$ \\
\hline 2 & $\begin{array}{l}\text { Residues in additional allowed regions } \\
\qquad[\mathrm{a}, \mathrm{b}, 1, \mathrm{p}]\end{array}$ & 92 & $7.5 \%$ & 42 & $8.5 \%$ \\
\hline 3 & $\begin{array}{l}\text { Residues in generously allowed regions } \\
\qquad[\sim \mathrm{a}, \sim \mathrm{b}, \sim 1, \sim \mathrm{p}]\end{array}$ & 8 & $0.7 \%$ & 2 & $0.4 \%$ \\
\hline 4 & Residues in disallowed regions & 4 & $0.3 \%$ & 3 & $0.6 \%$ \\
\hline 5 & $\begin{array}{l}\text { Number of non-glycine and non Proline } \\
\text { residues }\end{array}$ & 1228 & $100.0 \%$ & 494 & $100 \%$ \\
\hline 6 & $\begin{array}{l}\text { A number of end-residues (excl. Gly and } \\
\text { Pro) }\end{array}$ & 8 & & 4 & \\
\hline 7 & $\begin{array}{l}\text { Number of glycine residues (shown as } \\
\text { triangles) }\end{array}$ & 92 & & 24 & \\
\hline 8 & Number of Proline residues & 48 & & 18 & \\
\hline 9 & Total number of residues & 1376 & & 540 & \\
\hline
\end{tabular}

The aspartyl $\mathrm{b}$ semi aldehyde had shown higher binding energy of $-5.2 \mathrm{k}$. cal with homoserine dehydrogenase with 9 interacting amino acids and two hydrogen bonds than 2,3 Dihydrodipicolinate synthase enzyme with -4.5 k.cal of binding energy (Fig.-9), four interacting amino acids with four Hydrogen bonds. As the chemical mutagen, ENU caused a mutation in the homoserine dehydrogenase caused protein not to express or might have produced a protein which could not bind properly with Aspartyl B semi aldehyde diverted the Aspartyl semialdehyde to bind with 2,3 Dihydrodipicolinate synthase enzyme entered the dap pathway. As the binding energy is more for homoserine dehydrogenase enzyme it showed higher reactivity with the Aspartyl B semi aldehyde but lack of it caused the Aspartyl semialdehyde to bind with2,3 Dihydrodipicolinate synthase which directed to L -Lysine synthesis through producing L L diaminopimelate. Being a ddh recombinant strain the Corynebacterium glutamicum 
RASĀYAN J. Chem.

Vol. 13 | No. 2 |1245-1261| April - June | 2020

produced more ddh which deviated the 2,6 dicarboxylic acid away from reacting with acetyltransferase or Succinyl transferase to produce L Lysine.

The $L$ Lysine yield in the newly developed auxotrophic mutant of ddh recombinant strain of Corynebacterium glutamicum ATCC 13032 strain in the presence of Homoserine based amino acids

Auxotrophic ddh recombinant strain in the presence of methionine and threonine had produced $\mathrm{g} / \mathrm{l}$ of $\mathrm{L}$ Lysine, in the presence of Threonine only had produced $22.34 \mathrm{~g} / 1$ and $23.54 \mathrm{~g} / 1$ in methionine only and $22.92 \mathrm{~g} / \mathrm{l}$ of L Lysine in the absence of both methionine and Threonine from the auxotrophic recombinant mutant.
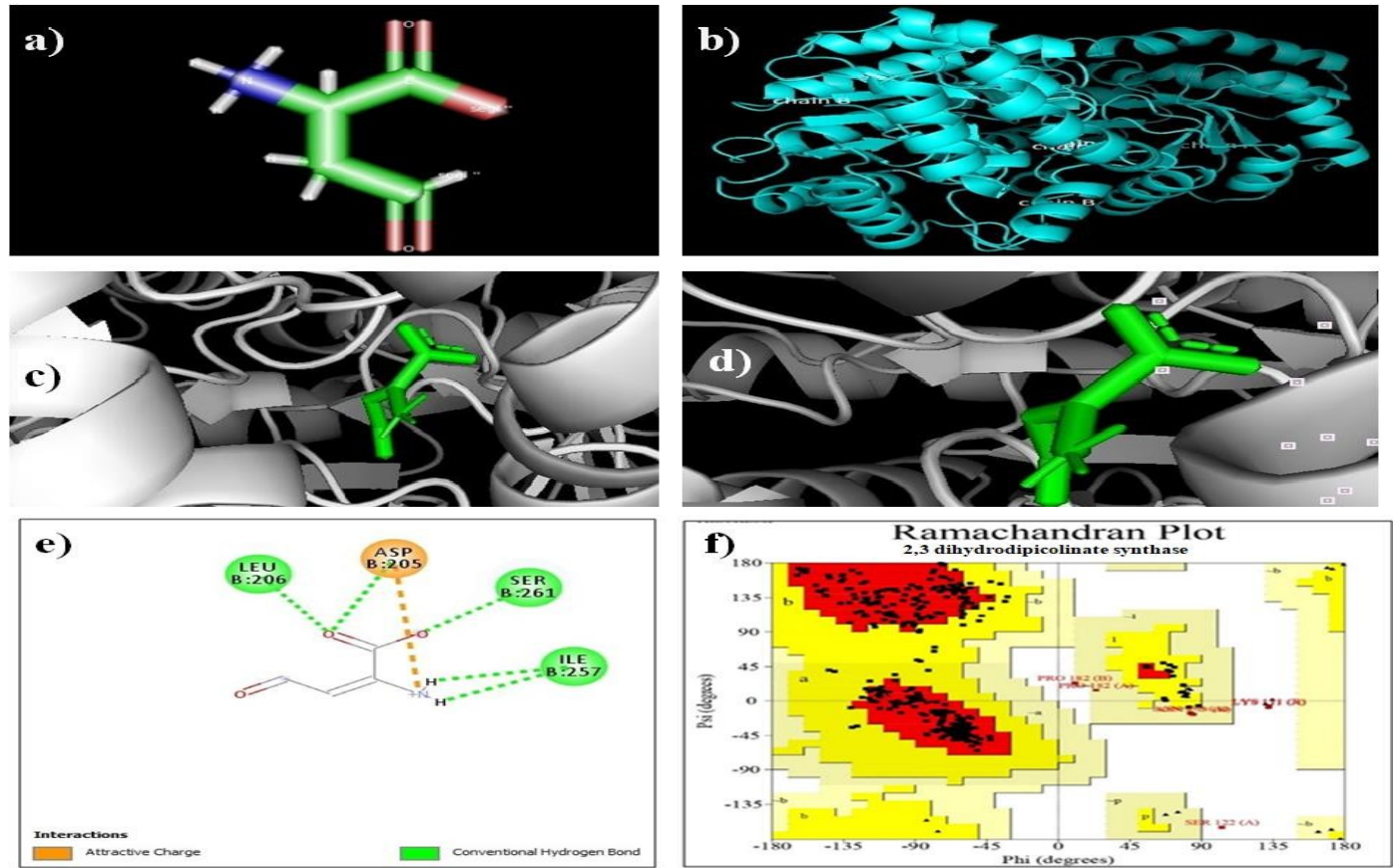

RMS distances from planarity
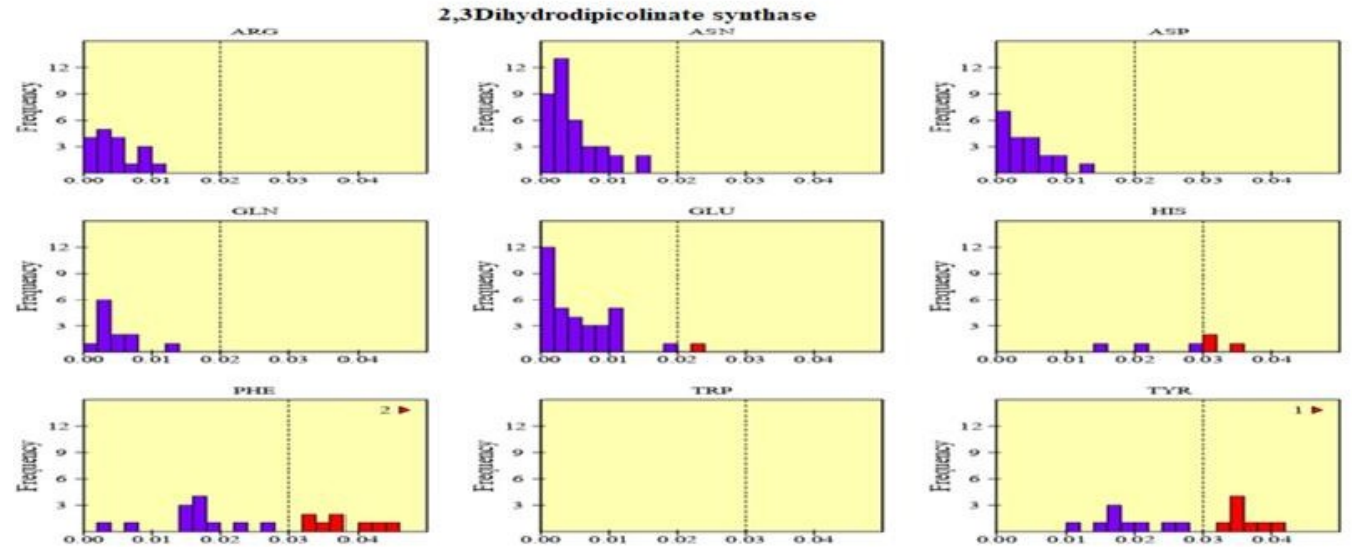

Fig.-9: (a) Ligand Aspartyl $\beta$ semialdehyde, (b) Protien2,3 Dihydrodipicolinate synthase, (c and d) Protein-ligand interaction, (e) lid plot analysis of Ligand Aspartyl $\beta$ semi aldehyde with ProtienProtien 2,3 Dihydrodipicolinate synthase : LEU (B:206), SER (B:261), ASP (B:205) and ILU (B:257)are the interacting amino acids ofprotien2,3 Dihydrodipicolinate synthase with 4 conventional H-bonds formed with the ligand Aspartyl $\beta$ semi aldehyde, (f). Ramachandran plot for DHPS with 90.05\% favored regions, (g) RMSD value of HSD between 1.5 to 2.0 for DHPS signifying the good quality of Protein to be docked with the ligand. 
RASĀYAN J. Chem.

Vol. 13 | No. 2 |1245-1261| April - June | 2020

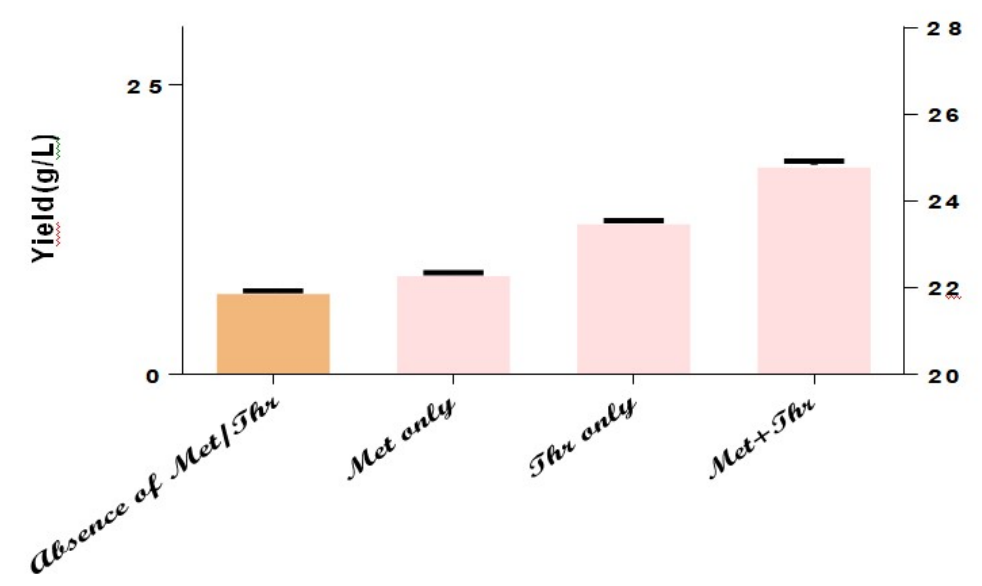

Fig.-10: L Lysine Yield of Auxotrophic mutant of ddh Recombinant strain of C. glutamicum.

In the presence of both Methionine and Threonine, the L Lysine Yield is $24.89 \mathrm{~g} / 1$, in the presence of threonine only the L Lysine yield is $23.54 \mathrm{~g} / 1$, methionine only is $22.34 \mathrm{~g} / 1$ and in the absence of Methionine and threonine is $21.92 \mathrm{~g} . / 1$ for the Auxotrophic mutant of ddh recombinant ATCC 13032 strain of C. glutamicum (Fig.-10).

The ddh Recombinant mutant produced more amounts of L Lysine under because of the effect chemical mutagenesis of ENU by blocking the Homoserine dehydrogenase of homoserine pathway diverting the aspartate $\beta$-semialdehyde to bind with 2,3 Dihydrodipicolinate synthase. The auxotrophic recombinant mutant had shown a yield $24.89 \mathrm{~g} / 1 \mathrm{~L}$ Lysine in the presence of threonine and Methionine.23.54, $\mathrm{g} / \mathrm{l}$ in the presence of threonine only and $22.34 \mathrm{~g} / 1$ in the methionine only and $22.92 \mathrm{~g} / 1$ without threonine and methionine in the media signifies the mutation had occurred in the Homoserine dehydrogenase which participates in the Homoserine pathway of the auxotrophic mutant of ddh recombinant Corynebacterium glutamicum ATCC 13032. Binding energy for the protein homoserine dehydrogenase of $-5.2 \mathrm{~K}$. Cal with one conventional hydrogen bond binds more strongly with -0.7 k.cal greater than 2,3 Dihydrodipicolinate synthase with $-4.5 \mathrm{~K}$.Cal with 4 conventional hydrogen bonds with aspartate $\beta$ semialdehyde. Due to the lack of Homoserine dehydrogenase in the auxotrophic mutant of ddh recombinant, the energy utilized in the synthesis of Threonine and Methionine by Homoserine pathway will be utilized in the L Lysine synthesis by binding with 2,3 Dihydrodipicolinate synthase to produce $\mathrm{L}$ Lysine through L L diaminopimelate (2,3 meso-DAP). Even the number of hydrogen bonds and interacting amino acids of the proteins play an important role in the diverting the Homoserine pathway to DAP pathway can be analyzed in the molecular docking analysis of Protein and ligand.

Being a recombinant for ddh gene, the recombinant mutant expressed more amounts of DDH enzyme which further diverts the strain from entering 3 enzymes involved pathways of acetyltransferase and Succinyl transferase to a single enzyme involved ddh pathway in the production of $\mathrm{L} \mathrm{L}$ diaminopimelate (2,3 meso-DAP) for the production of High yield of L Lysine.

The wild type mutant and ddh recombinant mutant had Chemical mutagen ENU induced blockage in the homoserine pathway and overexpression of ddh gene directed DAP synthesis in ddh recombinant strain with the involvement of fewer enzymes compared with Acetyltransferase and Succinyl transferase pathways lead to increased production of L Lysine than auxotrophic mutant Wild Type of C. glutamicum. Nearly $4.23 \mathrm{~g} / 1$ amount of L Lysine was increased in this newly developed Strain when compared with normal ddh recombinant strain which had a yield of $20.66 \mathrm{~g} / 1 \mathrm{~L}$ Lysine. The L Lysine Yield of Auxotrophic mutant of ddh recombinant is $6.32 \mathrm{~g} / 1 \mathrm{~L}$ Lysine Yield more than auxotrophic mutant wild type with a yield of $18.57 \mathrm{~g} / 1 \mathrm{~L}$ Lysine. In the case of Auxotrophic mutant of ddh recombinant strain shown the maximum yield in the presence of both threonine and methionine of $24.89 \mathrm{~g} / 1 \mathrm{~L}$ Lysine, 23.54 $\mathrm{g} / 1 \mathrm{~L}$ Lysine in the presence of threonine only, $22.34 \mathrm{~g} / \mathrm{lL}$ Lysine in the presence of only methionine, and finally $22.92 \mathrm{~g} / \mathrm{l}$ of L Lysine in the absence of both methionine and threonine. From this study, the 
amount of lysine production enhanced is discussed on the basis of molecular docking which further supported our results. Hence we developed an auxotrophic mutant from the ddh gene recombinant of Corynebacterium glutamicum ATCC 13032 which will be helpful in industrial L Lysine Production through this new Auxotrophic mutant (Fig.-11).

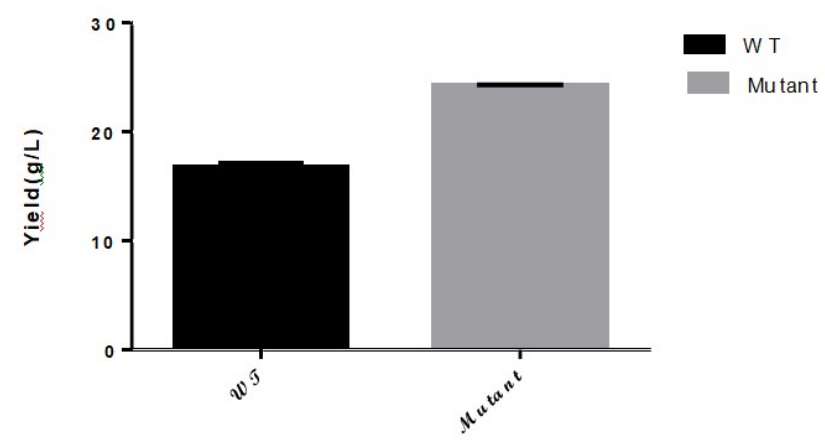

Fig.-11: Yield of L Lysine of Auxotrophic mutants of ddh recombinant and Wild Type C. glutamicum at Optimized conditions of ddh Recombinant mutant. R- L Lysine in an auxotrophic mutant of ddh Recombinant C. glutamicum ATCC 13032 is $24.89(\mathrm{~g} / \mathrm{l})$. L -Lysine in an auxotrophic mutant of wild type C. glutamicum ATCC 1303218.57 $(\mathrm{g} / \mathrm{l})$.

\section{CONCLUSION}

By culturing the chemically mutated ddh recombinant ATCC 13032 strain the L Lysine yield was increased to $24.89 \mathrm{~g} / \mathrm{l}$ at optimized parameters of $\mathrm{PH} 7.5$, temperature $30 \mathrm{C}$ and $96 \mathrm{hrs}$. of time of incubation compared to an auxotrophic mutant of wild type strain with a yield of $18.57 \mathrm{~g} / 1$ of L Lysine.

\section{ACKNOWLEDGEMENT}

I sincerely thank Science and Engineering Research Board (SB/FTP/ETA-168/2012, Dt: .20-52013,DST,Govt, New Delhi-110070) for founding this entire project and also to JNTUK Kakinada for enabling me to continue my research project.

\section{REFERENCES}

1. B. Mallaiah, T. Giri, E. Laxminarayana, M. Thirumala Chary and K. Shashikala, Organic and Medicinal Chemistry Letters, 4, 16 (2014)

2. Min Ju Lee and Pil Kim, Frontiers in Microbiology(2018), DOI:10.3389/fmicb.2018.02523

3. V. F. Wendisch and Bott M, CRC Press. Taylor \& Francis, pp. 377-396(2005), DOI: $10.1201 / 9781420039696$

4. S. Anastassiadis. Recent Patents Biotechnology, 1, 11(2007), DOI:10.2174/187220807779813947

5. A. H. Shah, A. Hameed, and G.M. Khan. International Journal of Medical Sciences, 2, 52 (2002), DOI: $10.3923 /$ jms.2002.152.157

6. O. Tosaka, Trends in Biotechnology, 1, 70(1983), DOI:10.1016/0167-7799(83)90055-0

7. M. Ikeda, Advances in Biochemical Engineering/Biotechnology, 79, 1(2003, DOI:10.1016/01677799(83)90055-0

8. J. Z. Xu, M. Han, J. L. Zhang, Y. F. Guo and W. G. Zhang. Amino Acids, 46, 2165(2014), DOI: $10.1007 / \mathrm{s} 00726-014-1768-1$

9. M. Hilliger, F. Haenel and J. Menz, Journal of Applied Microbiology 24, 437(1984), DOI: $10.1002 / \mathrm{jobm} .19840240704$

10. Leuchtenberger W, Huthmacher K and Drauz K. Applied Microbiology and Biotechnology, 69, 1 (2005), DOI:10.1007/s00253-005-0155-y

11. M. Patek, Springer, Heidelberg, 778(2007).

12. R. S. Hanson, R. L. Dillingham, P. Olson, G. H. Lee, D. Cue and F. J. Schendel, Kluwer Academic Publishers, Dordrecht, 227(1996), DOI:10.1007/978-94-009-0213-8_31 
RASĀYAN J. Chem.

Vol. 13 | No. 2 |1245-1261| April - June | 2020

13. T. Tryfona and T. Mak, Biochemistry, 40, 499(2005), DOI:10.1093/nar/gku989

14. S. Hirono, M. Sugimoto, E. Nakan, M. Izui and Y. Hayakawa, United States Patent 6090597(2000).

15. L. Liu, H. Yang, H. D. Shin, J. Li, G. Du and J. Chen, Applied Microbiology and Biotechnology, 97, 9597 (2013), DOI:10.1007/s00253-013-5250-x.

16. J. Y. Lee, Y. A. Na, E. Kim, H. S. Lee and P. Kim, Journal of Microbiology and Biotechnology. 26, 1341(2016), DOI:10.4014/jmb.2016.2607.1341

17. Van Ooyen J, Noack S, Bott M, Reth and L. Eggeling, Biotechnology \& Bioengineering, 109, 2070(2012), DOI: 10.1002/bit.24486

18. H. Ozaki, I. Shiio, Agricultural and Biological Chemistry, 47, 1569(1983), DOI: $10.1080 / 00021369.1983 .10865820$

19. G. E. Colón, M. S. Jetten, T. T. Nguyen, M. E. Gubler, M. T. Follettie, A. J. Sinskey and G. Stephanopoulos, Applied and Environmental Microbiology, 61, 74 (1995).

20. D. J. Reinscheid, W. Kronemeyer, L. Eggeling, B. Eikmanns and H. Sahm, Applied and Environmental Microbiology, 60, 126(1994)

21. M. Kircher, W. Pfeerle, Chemosphere, 43, 27 (2001).

22. G. M. Seibold, S. Auchter, J. Berens, Kalinowski and Eikmanns, Journal of Biotechnology, 124, 381 (2006) , DOI: 10.1016/j.jbiotec.2005.12.027

23. R. Q. Nelofer, M. Syed and X. Nadeem, Turkish Journal of Biochemistry, 33, 50 (2002).

24. A. H. Shah, G. M. Hameed and Khan, Pakistan Journal of Biological Sciences, 5, 80(2002), DOI: $10.3923 /$ pjbs.2002.80.83

25. A. H. Shah, S.U. Hameed, A. H. Rehman, Pakistan Journal of Zoology, 44(1), 141(2012).

26. C. B. Pham, H. Kataoka, and M. Matsumura, International Center for Biotechnology., 16, 506509 (1993).

27. M. V. Matos and N. Coello, Acta Cientifica Venezolana, 50, 233 (1999).

28. D. Hanahan, DNA Cloning, 1. IRL Press, Oxford (1985).

29. J. Ohnishi, A. S. Mitsuhashi, M. Hayashi, S. Ando, K. Yokoi, K. Ochiai and M. Ikeda, Applied Microbiology and Biotechnology,58, 217 (2002, DOI:10.1007/s00253-001-0883-6

30. C. Wittmann and E. Heinzle, Applied and Environmental Microbiology 68, 5843 (2002).

31. H. Nishida, M. Nishiyama, K. Nobuyuki, T. Kosuge, T. Hoshino and H. Yamane, Genome Research 9, 175 (1999) , DOI: 10.1101/gr.9.12.1175

32. A. Waterhouse, M. Bertoni, S. Bienert, G. Studer, G. Tauriello and Gumienny, Nucleic Acids Research, 46, W296 (2018), DOI:10.1093/nar/gky427

33. R. A. Laskowski, J. Jabłońska, L. Pravda, R. S. S. Vařeková, J. M. Thornton, Protein Science, 27, 129 (2018) , DOI: 10.1002/pro.3289

34. R. A. Laskowski, M. W. MacArthur, D. S. S. Moss and Thornton, Journal of Applied Crystallography, 26, 283 (1993), DOI:10.1107/S0021889892009944

35. M. Kalia, V. K. Yadav, P. K. Singh, S. Dohare, D. Sharma, S. S. Narvi and V. Agarwal, Biotech, 9(2), 40 (2019) , DOI:10.1007/s13205-019-1567-1

36. Uni Prot and Consortium, Nucleic Acids Research, 43, D204 (2015) , DOI:10.1093/nar/gku989

37. T. P. Dao, D. C. Nguyen, T. H. Tran, P. V. Thinh and V. Q. Hieu, Rasayan Journal of Chemistry 12(2), 666 (2019), DOI: 10.31788/RJC.2019.1225107

38. A. A. Parikesit and U. S. F. Tambunan, Rasayan Journal of Chemistry, 11(3), 1133(2018), DOI: $10.31788 /$ RJC.2018.1133038

[RJC-5416/2019] 